\title{
Climate change impact on the quality of freshwater resources and waste management in the context of 2030 Agenda on Sustainable Development
}

\author{
Cristiana MIC-SOARE \\ University of Bucharest, Bucharest, Romania \\ cristianamicsoare@gmail.com \\ Stelian-Mihai MIC \\ University of Bucharest, Bucharest, Romania \\ stelian.mic@mialegal.ro
}

\begin{abstract}
The importance of the effects of climate change has been emphasized on a variety of levels and from a number of different perspectives: on a country, regional or international level; affecting agriculture, energy, tourism, shipping, economic activities, various ecosystems as well as human health. It has been repeatedly recognized that climate change has a significant impact on freshwaters, including on their quality, availability and sustainability. From a different perspective, that of the circular economy, management strategies applied in respect to freshwaters have a direct impact on the climate. At the same time, improper waste management has a very high negative contribution to the latest climate changes, on one hand, and on the quality and availability of freshwater resources, on the other hand. Nevertheless, how all the three different above-mentioned elements - climate change, freshwater resources and waste management - are linked in the context of 2030 Agenda on sustainable development is yet to be thoroughly discussed in the scientific literature in the field of environmental law. Thus, by analysing a sample of the legal doctrine contributions published starting from 2016, as well as several official documents issued by the United Nations, we aimed to establish if all the three above-mentioned elements are interlinked and how they impact each other. As a result, we determined that there is a clear necessity for states to take unified measures to address climate change, protection and management of the freshwater resources and consistent waste management in the context of the Sustainable development goals (SDGs) introduced by the 2030 Agenda.
\end{abstract}

Keywords: 2030 Agenda on sustainable development, climate change, freshwater resources, waste management, interrelation.

\section{Introduction}

2030 Agenda for sustainable development /[2030 Agenda/] (United Nations General Assembly /[UNGA/], 2015) institutes a "plan of action for people, planet and prosperity", seeking to implement this plan by means of transformative actions in a collaborative partnership between countries and all other stakeholders (Preamble).

2030 Agenda states a number of 17 Sustainable Development Goals /[SDGs/] - figure 1 on the following page, divided into 169 targets undertaking to balance the economic, social and environmental dimensions of sustainable development (UNGA, 2015, Preamble).

Out of these SDGs, relevant for the purposes of this paper are mainly SDG 6 (Clean water and sanitation) and SDG 13 (Climate action). Additionally, SDG 12 (Responsible consumption and production), particularly target 12.4, as well as SDG 15 (Life on land), particularly target 15.1, also present interest to this analysis. According to SDG 6, states undertake to "ensure availability and sustainable management of water and sanitation for all", whereas per SDG 13, their goal is to 
"take urgent action to combat climate change and its impacts", although "acknowledging that the United Nations Framework Convention on Climate Change is the primary international, intergovernmental forum for negotiating the global response to climate change" (UNGA, 2015, p. 14). Further, SDG 12 refers to the need to "ensure sustainable consumption and production patterns" (UNGA, 2015, p. 14).

\section{SUSTAINABLE DEVELOPMENT}
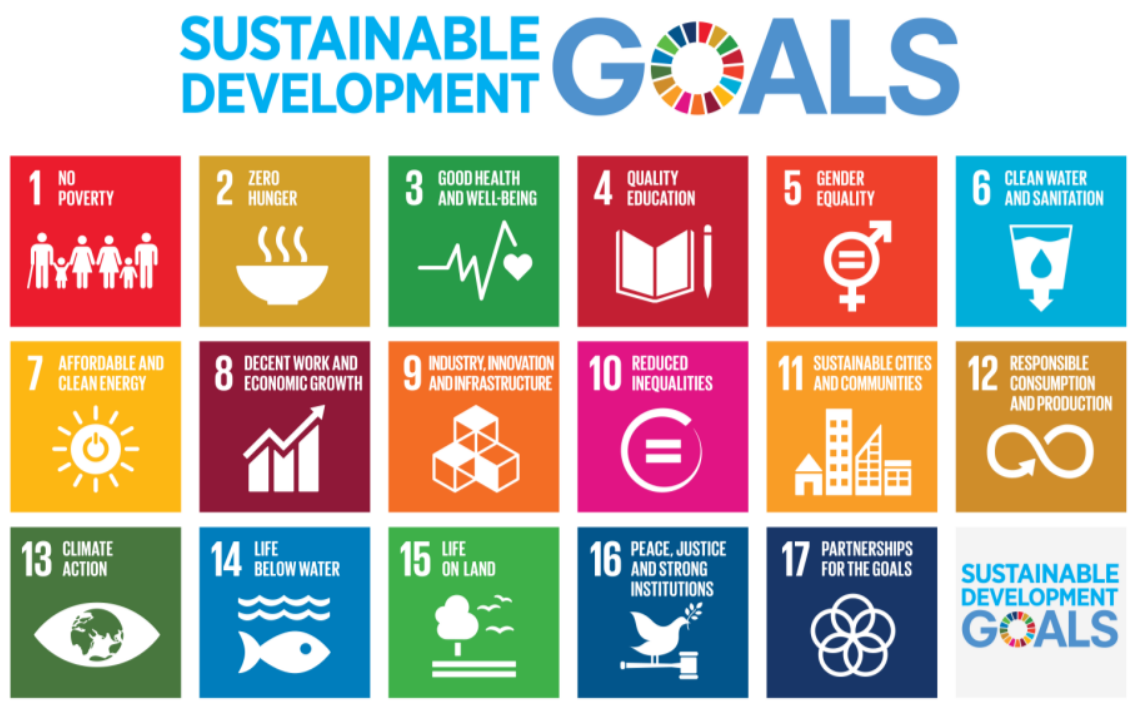

SUSTAINABLE DEVELOPMENT

Figure 1. SDGs set out in 2030 Agenda

Source: https://www.un-page.org/page-and-sustainable-development-goals.

As part of SDG 6 (Clean water and sanitation), states undertake, among other, to "improve water quality by reducing pollution, eliminating dumping and minimizing release of hazardous chemicals and materials" by 2030 (target 6.3), and respectively to "protect and restore water-related ecosystems, including ... rivers... and lakes" by 2020 (target 6.6, as stated in UNGA, 2015, p. 18).

As part of SDG 13 (Climate action), some of the purposes are to "strengthen resilience and adaptive capacity to climate-related hazards and natural disasters" (target 13.1) and to "integrate climate change measures into national policies, strategies and planning" (target 13.2, as stated in UNGA, 2015, p. 23), also making reference to "the global nature of climate change", which "calls for the widest possible international cooperation", while also being "determined to conserve and sustainably use ... freshwater resources" (UNGA, 2015, pp. 8-9). In this context, it is important to outline the fact that climate change is viewed as "one of the major stressors challenging the competency to attain the ecological, economic and social objectives that outline the SDG" (Bangar et al., 2020).

Target 12.4 of SDG 12 (Responsible consumption and production) refers to the necessity to "achieve environmentally sound management of ... wastes throughout their life cycle, ... and reduce their release to ... water ... in order to minimize their adverse impacts on human health and the environment" (UNGA, 2015, p. 22).

Target 15.1 of SDG 15 (Life on land) emphasizes the need to "ensure the conservation, restoration and sustainable use of terrestrial and inland freshwater ecosystems and their services ..." by 2020 .

It is very important to emphasize, for the purposes of this paper, that the goals set out by the 2030 Agenda are considered to be "integrated and indivisible", as well as "aspirational and 
global" (UNGA, 2015, p. 13), allowing the parties at the same time to pursue them according to their own strategies and national policies.

At the same time, we note that the current status of the earth's climate is shown to be mainly induced by anthropogenic activities, accelerating at a much higher rate than the natural processes aimed at countervailing such harmful activities (Arora et al., 2018).

In this context, this paper undertakes to answer the following main research question: how are measures regarding (i) climate change, (ii) the protection of freshwater resources, and respectively (iii) waste management to be interpreted against the background of the above-mentioned SDGs introduced by 2030 Agenda?

\section{Literature review}

Most of the materials reviewed for the purposes of this paper do not offer an integrative view over the complementarity and interdependency of climate change, freshwater and waste management in the context of the above-mentioned SDGs. Therefore, this chapter will analyse, in turn, aspects related to: the sustainable management of freshwater resources in the context of addressing climate change issues; the link between the sustainable management of freshwater resources and waste management; and the relation between climate change and waste management.

We note nonetheless that there are also authors addressing the impact of climate change on the rest of the SDGs (Bangar et al., 2020; Djebo et al., 2019), respectively analyses addressing the impact of water/freshwater on the rest of the SDGs (for example, UN Water, 2016; UNECE and WHO Europe, 2019; Ezbakhe, 2018; Ho and Goethals, 2021; Ho and Goethals, 2019).

\section{With reference to the fact that the sustainable management of freshwater resources is key to addressing climate change issues, and vice versa}

According to UNESCO \& UN-Water (2020), it can be derived from the interpretation of the 2030 Agenda as a whole that its purpose is to interlink and integrate all SDGs jointly. However, even though it is recognized that the sustainable management of freshwater resources and ecosystems stands at the root of the climate change-related SDG 13, they are still not addressed together either at global, or at national level. Therefore, it is important that mechanisms for coordination of climate and water management are established, particularly at national level (UNESCO and UN-Water, 2020).

It is further considered that water is a central connecting component between climate change and the other SDGs (UNESCO and UN-Water, 2020), thus also indicating the link between water, climate change and waste management issues. In further evidence to the statement above, we note the United Nations' Sustainable development goals report 2020 /[UN SDGs report 2020/], which, with reference to SDG 6, refers to the relation with climate change issues for least developed states and small island developing states (UN, 2020). Moreover, the implementation of SDG 6 and SDG 13 are considered as being "mutually supportive" (UN-Water, 2016).

It has been noted that the protection of water-related ecosystems, as well as the integrated water resource management steps are frequently covered by climate measures taken by states (Janetschek et. al., 2019, p. 9), "climate change having a fundamental impact on the global water cycle" (OECD, 2017). Climate change has been shown to have significant negative impacts on freshwater ecosystems (including lakes), on one hand, whereas, on the other hand, freshwater resources have an important role in mitigating the climate change effects (Ho and Goethals, 2021; Ho and Goethals, 2019). 
Against this background, it is considered that a global consensus related to water policy is emerging, respectively two goals complicated by the climate change-determined disruptions, namely (i) the fact that all nations should enjoy water security, and (ii) the fact that ecosystems should be managed for resilience taking into account the climate disruptions (Tarlock, 2018).

On a similar note, it is frequently considered that countries will need to pursue not only mitigation measures, but also various adaptation mechanisms in order to limit or, even more favourably, diminish the negative effects of climate change on water resources (for example, Bisselink et al., 2020). Countries will be forced to adapt to climate change-determined disruptions, taking into account the fact that, even if the internationally envisaged mitigation measures would be met, which seems to be extremely unlikely, the temperature increases would still not be halted (Tarlock, 2018).

Thus, water pollution control is considered as being a central element that could enhance the resilience for managing climate change hazards in the water sector (Bertule et al., 2018). In this context, consistently with the approach of the 2030 Agenda, it seems highly appropriate to include, within water protection mechanisms and programmes, also points regarding other interlinked aspects such as climate change adaptation and mitigation (Bennett and Ruef, 2016, Abell et al., 2019) or waste management, since the future development of freshwaters is highly dependent on various climate-related factors (Tortajada, 2016).

At the same time, however, taking into account the fact that there are many uncertainties, variables and a significant lack of data related to climate change (especially but not only subsequent to the COVID-19 pandemics), there are authors who consider that other factors - such as management, governance and policy issues, infrastructure development, technology and innovations, etc. - which are not climate-related have become more relevant than the climaterelated ones from the perspective of governance of freshwater systems (Tortajada, 2016, p. 2). We also note the increasing necessity that all stakeholders should be actively involved in articulating water resource management (Gupta and Goyal, 2020) and climate-related plans.

\section{With reference to the link between the sustainable management of freshwater resources and waste management}

UN SDGs report 2020 states that, even though progress has been made in the past, water pollution, degraded water-related ecosystems and cooperation over transboundary water basins represent issues that require increased attention (UN, 2020, p. 36).

In this context, we refer to the close interaction between SDG 6 (Clean water and sanitation) and SDG 12 (Responsible consumption and production), which is needed in order to ensure water quality and the improvement of "aquatic, marine and terrestrial ecosystem health by reducing the pollution load" (UN Water, 2016).

It is relevant to note that there are authors who make reference to the necessity of a circular economy model for waste management based on water (for example, Smol et al., 2020), which should include, among other, steps for reduction of waste-generated pollution at source and the application of efficient modern technologies for removing pollutants (including waste) from water.

Such necessity comes in the context that freshwater resources worldwide are increasingly polluted with various pollutants, including organic waste (UNESCO, UN-Water, 2020, p. 20).

Against this background, one of the main sources of pollution of freshwater resources, respectively of degradation of the corresponding ecosystems, is waste, plastic waste in particular posing significant threats to freshwater ecosystems (Williams et al., 2019). Presently, "waste ... is mounting" (UN, 2020, p. 48), with urban areas generating important amounts of solid waste. This 
aspect, coupled with inadequate waste management (inefficient or non-existing collection and reduction mechanisms and/or infrastructure), determines severe water contaminations (Koop and van Leeuwen, 2019). It is also noted that water ecosystems are globally contaminated with heavy metals, including by plastics, textiles, electronic waste, waste incineration residue, etc. (Arora et al., 2018, p. 311). This, in turn, leads also to very important losses of biodiversity in water bodies (Arora and Mishra, 2019).

It is thus considered essential that countries decrease their reliance on natural resources, on one hand, and increase recycling and circular economy tactics, on the other hand, so that the environmental pressure generated through the unsustainable use of natural resources is reduced (UN, 2020), also taking into account that it has been proven that recycling leads to "significant reductions in greenhouse gas (GHG) emissions" (Koop and van Leeuwen, 2019, p. 394). Moreover, waste technologies should also be restructured and significantly improved by innovation, taking into account also the water consumption and use efficiency of the respective technologies (Pires et al., 2019).

\section{With reference to the relation between climate change and waste management}

We notice that, even though climate change has its own SDG allocated in the 2030 Agenda (SDG 13), and waste-related issues are mainly touched upon in SDG 12 (Responsible consumption and production), there is no clear link regarding the impact one may have on the other, being discussed as distinct environmental issues.

Nonetheless, it is considered that the adequate implementation of SDG 12 could represent an aid for reducing waste, as well as for enhancing the management of various waste materials such as chemicals. This, in turn, would also have a positive impact on the adverse environmental effects of globalisation, among which climate change is encompassed (Correia et al., 2018). The idea of a circular economy approach is frequently put forward in the reviewed literature in the context of waste management issues, including from the perspective of promotion of sustainable use of natural resources by reducing the generated waste, particularly by means of waste prevention, reuse and recycling (Pires et al., 2019).

Plastic pollution is frequently analysed in relation to climate change, since "plastic has a large and rapidly growing greenhouse gas footprint, primarily in its production phase and secondarily upon incineration and decomposition", which aggravates climate disruptions (EIA, 2020 , p. 10). Thus, aside from negatively affecting the biodiversity of water and freshwater ecosystems, it also contributes to the intensification of climate change (Williams et al., 2019).

Taking the above into account, in order to support the contribution of solid waste management in relation to the achievement of the SDGs included in 2030 Agenda, it is recommended that waste management policies and regulations, as well as various economic and information instruments encompass also specific mitigation and adaptation mechanisms related to climate change (Pires et al., 2019). As example of another specific potential measure for reducing the level of greenhouse gas emissions - the significant increase of which poses such serious threats to the global climate - we also refer to the investment in low-carbon infrastructure, such as the physical networks used for providing water, energy, waste management in urban areas (GomezEcheverri, 2018). 


\section{Methodology}

The research conducted for this paper is primarily based on resources linked to the 2030 Agenda, considered in relation to climate change, quality and protection of freshwater resources and waste management.

The basic research question of the present paper is how are measures regarding (i) climate change, (ii) the protection and quality of freshwater resources, and respectively (iii) waste management, to be understood from the perspective of SDG 6, SDG 12 and SDG 13 as introduced by 2030 Agenda.

For this purpose, we conducted a search of the terms "2030 Agenda", "climate change", freshwater and waste on https://scholar.google.com/, and applied the following filtering methods: (a) the materials were sorted by relevance, automatically by the above-mentioned search engine; (b) the materials had to be published after the year 2016 (being the year subsequent to the adoption of the 2030 Agenda); (c) from the approximately 4020 results, we performed a preliminary screening of records by title and/or abstract, through the first 55 pages of results, representing the first 550 materials; (d) we did not take into consideration materials with a more specific related theme (such as agriculture, food, nuclear technology, fashion, tourism, mining, health, human rights, migration, etc.); (e) the research focused mainly on the legal situation deriving from various United Nations-related or -issued materials; (f) the search only considered articles in English.

Secondary materials identified in the ones reviewed per the above have also been taken into consideration, where relevant.

In addition, we analysed various United Nations publications considered relevant in the context of the research questions of this paper.

\section{Results and discussions}

The 2030 Agenda sets out, as shown above, a total number of 17 goals, out of which a number of 13 goals relate directly to the environment. Even though the 2030 Agenda theoretically has an integrative and holistic nature, it is considered by certain authors as in fact potentially fragmenting the environmental governance at a global level, for example by approaching climate action, life on land and life below water in three separate SDGs (Kim, 2016). Moreover, the SDGs are considered as not being able "to generate major architectural reforms or new integrative practices that will significantly reduce the fragmentation of the global governance system at large" (Underdal and Kim, 2017, p. 254).

While we mostly agree in principle with the above statement, we consider that it is essential that states, at a regional and national level, take appropriate measures to integrate the necessary solutions in order to achieve the purposes set out in SDG 6, SDG 12 and SDG 13, as discussed in this paper. Such an approach could help states avoid or at least mitigate potential harming environmental effects, while identifying "synergies and complementarities" between the envisaged measures and targets (in this regard, please see also Correia et al., 2018, p. 37). This may be easier from a theoretical rather than practical point of view, given the - sometimes radical - differences of development and status of states (among others, from an economic, technological, or even natural resources' perspective). Nevertheless, we are of the view that the key to achieving these goals is the sustainability of the measures taken, as well as the comprehensive attitude of states towards meeting the targets.

From a simplified perspective, we consider that there is a close and very significant interrelation between waste (and respectively waste management), freshwater resources and the 
quality and sustainability thereof, and climate change, since (i) waste has negative effects both on freshwater resources and on the global climate, (ii) climate change has a significant impact on water / freshwater resources and ecosystems, whereas at the same time (iii) negatively affected freshwater resources are not able to sustain climate disruptions. This relation is briefly exposed in Figure 2 below.

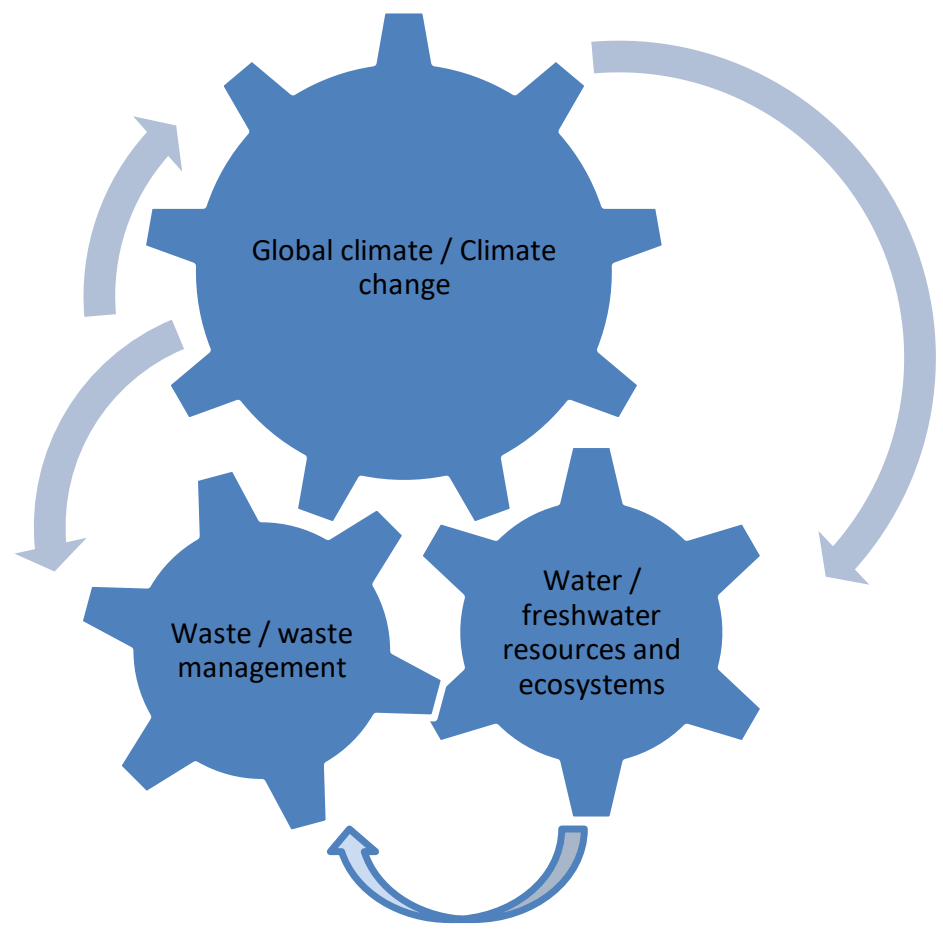

Figure 2. Brief interrelation between waste, freshwater resources and ecosystems and climate change

Source: own creation.

As such, we observe that there is an urgent need to holistically approach the achievement of the SDGs impacting on the freshwater resources and ecosystems, on climate change and on waste management issues. This can be done, from a general perspective, through designing measures such as those for ensuring the sustainable management of water resources and treating polluted waters, the sustainable waste and pollution management, correlated with measures for combating climate change, as well as through introducing green technologies (in this regard, please see also Arora et al., 2018). Equally important, we agree that, from a more particular perspective, the users and affected parts of society need to be closely involved in framing more adequate and stronger policies and regulations for the development and management of the above aspects (in this regard, please see also Tortajada, 2016).

\section{Conclusion}

Although we notice that the 2030 Agenda partly lacks coherence, which could lead to implementation challenges (Kim, 2016), we consider that, by means of states choosing to apply, at regional and national level, a holistic and integrative approach, SDGs 6, 12 and 13 discussed herein can be concluded as interlinking the waste management with the quality of freshwater resources and respectively with the climate change impacts thereof. 
In this context, we are of the view, in line with other authors, that the 2030 Agenda represents a significant - if not perhaps the most significant (Pires et al., 2019) - challenge for solid waste management, being so intrinsically linked to the highly problematic issues posed by climate change and pollution of water resources. Thus, tackling the global waste crisis, among other by means of "ensuring access to adequate, safe, and affordable solid waste collection services for all and by eliminating uncontrolled dumping and open burning" (Rodic \& Wilson, 2017), would determine an improved sustainability of water resources, as well as of the global climate and its effects.

At the same time, we note on one hand the global nature of the water pollution concern, affecting severely the sustainable development (Qi et al., 2020), with water quality degradation being "a threat to not only human health and the environment, but also economic growth and social progress" (Ezbakhe, 2018). On the other hand there is also the climate emergency situation in which the world currently is (Arora and Mishra, 2019). In this context, by enhancing the water management, climate change issues should also be consequently improved (Koop and van Leeuwen, 2019), and vice versa, by appropriately and urgently addressing climate-related problems, the sustainability of water resources and ecosystems should be better ensured.

While discussing water and waste management sustainability, due recognition must be also given to the potential impacts, as well as the mitigation and adaptation mechanisms of climate change (in this regard, please see also Earle and Neal, 2017).

Supplementary to the international approach described above, in order to have a starting point locally in Romania and consistent regulatory support in tackling from an integrative perspective the specific issues of water pollution, waste management and climate change, we consider that at least the following policy and regulatory developments should be considered: (A) the issuing of specific regulations providing for increased penalties (a) for recurring offenders in respect of (i) water pollution or (ii) breaches in waste management or (iii) climate-related actions; respectively (b) for actions/inactions with an increased negative effect on population or over a significant number of persons (e.g. leakages from illegal or defective solid waste deposits contaminating the local drinking water resources or leakages/illegal or defective storage of radioactive waste contaminating the water resources); (B) the exclusion of the currently applicable legal provisions stating that if the penalties applied in respect with environmental breaches are paid within 48 hours they are diminished to half; (C) the issuing of specific provisions providing for alternative obligations in respect of consistent industrial equipment management and penalties also for breaches of such alternative obligations which may lead to environmental damages (e.g. imposing an obligation to refurbish industrial/waste management equipment once at a specific period of time, at least to prevent the resulting substances from leaking into the soil/groundwater, drinking water or freshwater resources); (D) the removal of any statute of limitation in respect of the right to action against the breach of at least the environmental provisions regarding the contaminating of water resources and negligent or irresponsible waste management, considering the specific consequences of the ecologic damages, the rather murky character of pollution and (E) the establishing of a central national body with coordination and support powers for the programmes supported by the various environmentally-focused NGOs.

To conclude, even though the actual means of achieving the balance between water, waste and climate sustainable development will most frequently differ from region to region, or from country to country, the 2030 Agenda sets out an important global framework for achieving the sustainable development targets envisaged therein. 
Last but not least, we note that the research conducted for the purpose of this paper is limited, particularly taking into account the selection of the analysed materials, as detailed above in the Methodology section. Thus, the authors did not undertake to review and discuss all the existing resources in the field of the 2030 Agenda, climate change, protection of freshwater resources and waste management. This contribution should thus be read taking these main limitations into consideration.

\section{References}

Abell, R., Vigerstol, K., Higgins, J., Kang, S., Karres, N., Lehner, B., Sridhar, A., \& Chapin, E. (2019). Freshwater biodiversity conservation through source water protection: Quantifying the potential and addressing the challenges. Aquatic Conserv: Mar Freshw Ecosyst., 29, 1022-1038, https://doi.org/10.1002/aqc.3091.

Arora, N. K., Fatima, T., Mishra, I., Verma, M., Mishra, J., \& Mishra, V. (2018). Environmental sustainability: challenges and viable solutions. Environ Sustain, 1(4), 309-340, https:// doi.org/10.1007/s42398-018-00038-w.

Arora, N. K. \& Mishra, I. (2019). United Nations Sustainable Development Goals 2030 and environmental sustainability: race against time. Environmental Sustainability, 2, 339-342, https://doi.org/10.1007/s42398-019-00092-y.

Bangar, V., Goyal, R., \& Pandey, R. (2020). Climate Change Responses and Sustainable Development: Integration of Mitigation and Adaptation. In: Hazra, S., \& Bhukta, A. (eds). Sustainable Development Goals. An Indian perspective. Sustainable Development Goals Series. Springer, https://doi.org/10.1007/978-3-030-42488-6.

Bennett, G., \& Ruef, F. (2016). Alliances for green infrastructure: State of watershed investment 2016, Forest Trends, Ecosystem Marketplace, Retrieved from https://www.foresttrends.org/wp-content/uploads/2017/03/2016SOWIReport121416.pdf.

Bertule, M., Appelquist, L. R., Spensley, J., Trærup, S. L. M., \& Naswa, P. (2018). Climate change adaptation technologies for water: A practitioner's guide to adaptation technologies for increased water sector resilience, UNEP DTU Partnership, Retrieved from https:// orbit.dtu.dk/en/publications/climate-change-adaptation-technologies-for-water-a-practitio ners-.

Bisselink, B., Bernhard, J., Gelati, E., Adamovic, M., Guenther, S., Mentaschi, L., Feyen, L., \& de Roo, A. (2020). Climate change and Europe's water resources, EUR 29951 EN, Publications Office of the European Union, Luxembourg, https://doi.org/10.2760/15553, JRC118586.

Correia, F., Erfurth, P., \& Bryhn, J. (2018). The 2030 Agenda: The roadmap to GlobALLization. Department of Economic and Social Affairs Working Paper no. 156, ST/ESA/2018/ DWP/156, Retrieved from https://www.un.org/esa/desa/papers/2018/wp156_2018.pdf.

Djebo, A., Janetschek, H., Brandi, C. \& Iacobuta, G. (2019). Connections between the Paris Agreement and the 2030 Agenda. The case for policy coherence. Stockholm Environment Institute, Working Paper, Retrieved from https://www.sei.org/wp-content/uploads/2019/ 08/connections-between-the-paris-agreement-and-the-2030-agenda.pdf.

Earle, A., \& Neal, M. J. (2017). Inclusive Transboundary Water Governance. In Karar, E. (ed), Freshwater Governance for the 21 st Century, Springer Open, https://doi.org/10.1007/9783-319-43350-9.

Environmental Investigation Agency /[EIA/] (2020). Convention on Plastic Pollution. Toward a new global agreement to address plastic pollution, Retrieved from https://eia- 
international.org/wp-content/uploads/EIA-report-Convention-on-Plastic-Pollution-singlepages-for-print.pdf.

Ezbakhe, F. (2018). Addressing Water Pollution as a Means to Achieving the Sustainable Development Goals. Journal of Water Pollution and Control, 1, 1:6. Retrieved from https://www.imedpub.com/articles/addressing-water-pollution-as-a-means-to-achievingthe-sustainable-development-goals.php?aid=22766.

Gomez-Echeverri, L. (2018). Climate and development: enhancing impact through stronger linkages in the implementation of the Paris Agreement and the Sustainable Development Goals (SDGs). Phil. Trans. R. Soc. A, 376: 20160444, http://dx.doi.org/10.1098/rsta.2016. 0444.

Gupta, S., \& Goyal, S. (2020). Sustainability of River Water Resources Under the Influence of Climate Change. In Surampalli, R. Y., Zhang, T. C., Goyal, M. K., Brar, S. K., \& Tyagi, R.D. (eds), Sustainability: Fundamentals and Applications. First Edition. John Wiley \& Sons Ltd.

Ho, L. T., \& Goethals, P. (2021). Imperiled Lake Ecosystems, Reference Module in Earth Systems and Environmental Sciences, https://doi.org/10.1016/b978-0-12-821139-7.00028-3.

Ho, L. T., \& Goethals, P. (2019). Opportunities and Challenges for the Sustainability of Lakes and Reservoirs in Relation to the Sustainable Development Goals (SDGs), Water, 11, 1462, https://doi.org/10.3390/w11071462.

Janetschek, H., Brandi, C., Dzebo, A., \& Hackmann, B. (2019). The 2030 Agenda and the Paris Agreement: voluntary contributions towards thematic policy coherence, Climate Policy, https://doi.org/10.1080/14693062.2019.1677549.

Kim, R. E. (2016). The nexus between international law and the sustainable development goals. Review of European, Comparative and International Environmental Law, 25 (1), 15-26, https://doi.org/10.1111/reel.12148.

Koop, S. H. A., \& van Leeuwen, C. J. (2019). The challenges of water, waste and climate change in cities. Environ Dev Sustain, 19, 385-418, https://doi.org/ 10.1007/s10668-016-9760-4.

OECD (2017). Water and climate: from risk management to investment opportunity. $O E C D$ Observer, 312 (4). OECD. Retrieved from https://www.oecd-ilibrary.org/docserver/dd883 cf5-en.pdf?expires=1614942155\&id=id\&accname=guest $\&$ checksum=214D5CD89A3AE 6C54FF903927B361DA8.

Pires, A., Martinho, G., Rodrigues, S., \& Gomes, M.I. (2019). Sustainable Solid Waste Collection and Management. Springer International Publishing AG, part of Springer Nature. https://doi.org/10.1007/978-3-319-93200-2.

Qi, Y., Bhunia, P., Zhang, T. C., Luo, F., Lin, P., \& Chen, Y. (2020). Environmental Degradation and Sustainability. In Surampalli, R. Y., Zhang, T. C., Goyal, M. K., Brar, S. K., \& Tyagi, R.D. (eds), Sustainability: Fundamentals and Applications, First Edition, John Wiley \& Sons Ltd.

Rodic, L., \& Wilson, D. C. (2017). Resolving governance issues to achieve priority sustainable development goals related to solid waste management in developing countries. Sustainability, 9, 404, https://doi.org/10.3390/su9030404.

Smol, M., Adam, C., \& Preisner, M. (2020). Circular economy model framework in the European water and wastewater sector, Journal of Material Cycles and Waste Management, 22, 682-697.

Tarlock, A. (2018). Western water law and the challenge of climate disruption. Environmental Law, 48(1), 1-27, Retrieved from http://www.jstor.org/stable/44633531. 
Tortajada, C. (2016). Water, Governance, and Infrastructure for Enhancing Climate Resilience. In Tortajada, C. (ed). Increasing resilience to climate variability and change. The roles of infrastructure and governance in the context of adaptation. Water Resources Development and Management. Springer Science+Business Media Singapore, https://doi.org/10.1007/ 978-981-10-1914-2.

UN-Water (2016). Water and Sanitation Interlinkages across the 2030 Agenda for Sustainable Development, Retrieved from https://www.unwater.org/publications/water-sanitationinterlinkages-across-2030-agenda-sustainable-development/.

Underdal, A., \& Kim, R. E. (2017). The Sustainable Development Goals and Multilateral Agreements. In Kanie, N., \& Biermann, F. (eds). Governing through Goals. Sustainable Development Goals as Governance Innovation. Massachusetts Institute of Technology.

UNECE \& World Health Organization - Regional Office for Europe /[WHO Europe/] (2019). Protocol on Water and Health and the 2030 Agenda: A Practical Guide for Joint Implementation, Retrieved from https://unece.org/DAM/env/water/publications/WH16 SDGGuide/ECEMP.WH16ENG.pdf.

UNESCO \& UN-Water (2020). The United Nations world water development report 2020: water and climate change, Retrieved from https://unesdoc.unesco.org/ark:/48223/pf0000372985. locale $=$ en.

United Nations (2020). The sustainable development goals report 2020. Retrieved from https:// unstats.un.org/sdgs/report/2020/The-Sustainable-Development-Goals-Report-2020.pdf.

United Nations General Assembly (2015). 70/1. Transforming our world: the 2030 Agenda for Sustainable Development. Resolution adopted by the General Assembly on 25 September 2015. Seventieth session. Agenda items 15 and 116. A/RES/70/1 distr. 21 October 2015, Retrieved from https://www.un.org/ga/search/view_doc.asp?symbol=A/RES/70/1\&Lang $=\mathrm{E}$.

Williams, M., Cower, R., Green, J., Whitebread, E., Lenkiewicz, Z., \& Schroder, P. (2019). No time to waste. Tackling the plastic pollution crisis before it's too late, Retrieved from https://opendocs.ids.ac.uk/opendocs/bitstream/handle/20.500.12413/14490/J32121_No_ti me_to_waste_web.pdf? sequence $=1$ \&isAllowed $=\mathrm{y}$. 